\title{
Liquid-Liquid Equilibrium Data for the Ternary Systems of Palm Oil + Ethyl Lactate + Phytonutrients (Carotenes and Tocols) at $303.15 \mathrm{~K}$
}

\author{
Y. L. Kua, S. Gan, A. Morris, and H. K. Ng
}

\begin{abstract}
Experimental and thermodynamic modeling studies of liquid-liquid equilibria for two model systems of $\beta$-carotene and $\gamma$-tocotrienol in palm oil + ethyl lactate were performed at $303.15 \mathrm{~K}$ and atmospheric pressure in an effort to explore the potential application of ethyl lactate as a green and safe agrochemical solvent to recover carotenes and tocols from palm oil. The experimental data were correlated by Universal QuasiChemical (UNIQUAC) model while the thermodynamic data enables simulation of liquid-liquid extractors for phytonutrients recovery from palm oil as well as the prediction of energy requirement, equipment sizing and phase compositions for the oil- and solvent-rich phases. The results showed that ethyl lactate favors the extraction of phytonutrients from palm oil especially tocols due to their higher polarity and separation factors as compared to carotenes.
\end{abstract}

Index Terms - Carotene, ethyl lactate, palm oil, tocol.

\section{INTRODUCTION}

Carotenes are important precursors of vitamin A and are also natural antioxidants in combating several degenerative diseases including cardiovascular diseases, cancers, immunity and macular degeneration. Crude palm oil contains $500-700 \mathrm{ppm}$ of carotenes with approximately $56 \%$ of $\beta$-carotene [1]. The vitamin A activity of $\beta$-carotene, in terms of retinol equivalent, is 2 times higher than other provitamin A carotenes [2]. Therefore, palm oil has 15 times more retinol equivalent than carrots and 300 times more than tomatoes [3].

Tocols, including tocopherols and tocotrienols, are commonly known as vitamin E. They protect the body against oxidative damage, skin damage and aging by UV-radiation. Additionally, they help to boost the immune system, fight against infections and prevent the occurrence of old age cataract. As compared to tocopherol, tocotrienol has been reported to be more effective due to its unsaturated chain, which facilitates cell penetration and is highly antioxidative [4]. Tocotrienol was also reported to regulate cholesterol level, and prevent cancers, stroke and fats accumulation in liver [5]-[8]. Tocopherol is commonly found in many vegetable oils including cottonseed, groundnut and olive oil while palm and rice bran oil are among the richest natural sources of tocotrienol. Palm oil has 600-1000 ppm of tocols, with $78.7 \%$ of tocotrienol [9].

Palm oil is obtained from oil palm fruits (Elaeis guineensis/tenera) through screw pressing at high pressure.

\footnotetext{
Manuscript received January 6, 2017; revised May 5, 2017.

Yin Leng Kua, Suyin Gan, Andrew Morris, and Hoon Kiat Ng are with the University of Nottingham, Malaysia (e-mail: kebx4kye@nottingham.edu.my, suyin.gan@nottingham.edu.my, morris.andrew@nottingham.edu.my, hoonkiat.ng@nottingham.edu.my).
}

After oil refining through either physical or chemical processes, palm oil is the vegetable oil most consumed in the world, being $35.05 \%$ in 2015/16 [10]. Oil palm is the highest oil-producing plant with a yield of approximately 4 ton of oil per hectare per year. It is mainly planted, produced and exported from Indonesia and Malaysia. As compared to chemical refining process, physical refining is commonly used for palm oil due to better yield at lower cost. During physical oil refining process, carotenes are first partially removed by adsorption on activated bleaching earth, followed by high temperature steam deodorization which destroys the chromogenic properties of the remaining carotenes to produce a light yellow palm oil. Even though tocols are more thermally stable than carotenes, near to 50\% of the tocols will be stripped off along with free fatty acids (FFA), sterols and squalene into palm fatty acid distillate (PFAD) during deodorization step. Thus, there is a need to recover these phytonutrients from the oil before further refining process.

As both the extracted carotenes and tocols will be used as food fortifiers, the use of non-toxic, non-corrosive and non-carcinogenic solvents which are safe for human consumption is crucial. While many of the commonly used petrochemical solvents are known to pose certain degree of toxicity, ethyl lactate is a suitable candidate solvent because it is novel, green and safe. It is produced from carbohydrate feedstocks from the corn and soybean industries and it is present naturally in foods such as wine, beer, chicken and fruits. It is also non-ozone depleting, non-hazardous air pollutant and it is biodegradable into harmless compounds such as carbon dioxide $\left(\mathrm{CO}_{2}\right)$ and water. The US Environmental Protection Agency (USEPA) approved the solvent as a Significant New Alternatives Policy Program (SNAP) solvent while US Food and Drug Administration (USFDA) has approved its direct use in food and pharmaceutical products. It is generally recognized as a safe (GRAS) solvent. Ethyl lactate exerts polarity in the range of acetonitrile and $\mathrm{n}$-hexane. It is capable of forming intra- and inter-molecular hydrogen bonding [11]. Also, it has the ability to form Van der Waals interactions in oils [12]. As a result, ethyl lactate can dissolve in both aqueous and hydrocarbon environments and is capable of extracting compounds of a wide range of polarity [13].

Ethyl lactate has been reported to extract various phytonutrients mainly from solid matrix [13], [14]-[19]. From oil samples, [20] and [21] reported the liquid-liquid equilibrium data on the recovery of squalene and tocopherol from olive oil. Literature on the liquid-liquid equilibrium data of oil-deacidification systems by alcoholic solvents have been extensively published. Some of the papers also 
considered the partition of nutraceutical compounds by assuming that they are present at infinite dilution [22]-[24]. The distribution coefficients were reported instead of the liquid-liquid equilibrium data and these compounds are preferably retained in the oil rather than being extracted.

In this paper, ternary systems of palm oil + ethyl lactate + $\beta$-carotene and $\gamma$-tocotrienol were studied for the first time in order to examine the potential of ethyl lactate as a novel, green and safe solvent to extract the phytonutrients from palm oil in liquid-liquid extractors. Cloud points and upper critical solution temperature (UCST) of the binary system of palm oil + ethyl lactate are reported to examine the mutual miscibility of the system. Subsequently, the experimental data is used to adjust the binary interaction parameters of the UNIQUAC model in order to predict the liquid-liquid phase equilibria behavior of the pseudoternary systems.

\section{MATERIAL AND METHODS}

\section{A. Chemicals}

(S)-(-)-ethyl lactate (99\% purity) and n-hexane (HPLC grade) were obtained from Merck. $\beta$-carotene (99.4\% purity) originated from Calbiochem while $\gamma$ - tocotrienol (97\% purity) were bought from Davos Life Science (Singapore). Acetonitrile (HPLC grade) and dichloromethane (99.8\% purity) were obtained from Labscan. 2-propanol (HPLC grade) came from Fisher while palm oil (Brand Saji) was purchased from local grocery store in Malaysia.

\section{B. Cloud Point Determination}

Cloud point (or transition temperature) is the temperature at which the solution turns turbid as an indication of single- to two-phase transition for binary or higher level system. A total of $14.5 \mathrm{~g}$ of solution was prepared in a glass sample bottle by weighting the corresponding amounts of palm oil and ethyl lactate on a precise analytical balance with $0.0001 \mathrm{~g}$ accuracy. The solution was agitated in a temperature-controlled water bath with a calibrated digital thermometer inserted. The solution was first heated up until it became clear (single phase). Next, the water bath was cooled gradually until the cloud point was observed. Three measurements were taken with difference of no more than $0.3^{\circ} \mathrm{C}$.

\section{Liquid-Liquid Equilibria Measurements}

A total of $14.5 \mathrm{~g}$ of solution was prepared in a glass sample bottle by weighting the corresponding amounts of palm oil + ethyl lactate $+\beta$-carotene and $\gamma$-tocotrienol on a precise analytical balance with $0.0001 \mathrm{~g}$ accuracy. The solution was agitated in a temperature-controlled water bath with a calibrated digital thermometer inserted to monitor the temperature at $303.15 \pm 0.5 \mathrm{~K}$ for $3 \mathrm{~h}$. After that, the solution was left to settle in an oven at $303.15 \mathrm{~K}$ for $24 \mathrm{~h}$. Temperature as low as $303.15 \mathrm{~K}$ was chosen in order to preserve the heatand light-sensitive phytonutrients. The top (oil-rich) and bottom (solvent-rich) phase were then carefully withdrawn by gas-tight needle syringe (SGE Analytical Science) for high performance liquid chromatography (HPLC) analysis of $\beta$-carotene and $\gamma$-tocotrienol. Ethyl lactate content in both phases was determined gravimetrically after solvent evaporation. At least three experimental data were obtained to adjust the parameters of UNIQUAC model.

\section{HPLC Analysis}

An Agilent 1260 Infinity Series HPLC system was used along with a quarternary pump, an autosampler, a variable wavelength detector (VWD) and ChemStation software for system control and data collection. $\beta$-carotene was eluted from Purospher STAR RP-18 encapped column $(5 \mu \mathrm{m} ; 4.6 \times$ $250 \mathrm{~mm})$. The mobile phase consisted of $85 \%$ acetonitrile and $15 \%$ dichloromethane at $1.5 \mathrm{~mL} / \mathrm{min}$. The sample was diluted by ethyl lactate and $20 \mu \mathrm{L}$ of analyte was injected per analysis. The detector was set at $450 \mathrm{~nm}$ and the total run time was $25 \mathrm{~min}$. $\gamma$ - tocotrienol was eluted from Zorbax Rx-SIL column $(5 \mu \mathrm{m} ; 4.6 \times 250 \mathrm{~mm})$. The mobile phase consisted of $99 \%$ of $n$-hexane and $1 \%$ of 2-propanol at 0.8 $\mathrm{mL} / \mathrm{min}$. The sample was re-dissolved in $\mathrm{n}$-hexane and $20 \mu \mathrm{L}$ of analyte was injected per analysis. The detector was set at $292 \mathrm{~nm}$ and the total run time was $15 \mathrm{~min}$. All the mobile phase and analyte were filtered through $0.45 \mu \mathrm{m}$ nylon (polar) or polytetrafluoroethylene (PTFE) (non-polar) membrane before use.

\section{E. Thermodynamic Modeling}

UNIQUAC model is an activity coefficient equation to predict the highly non-ideal systems [25]. It is suitable for complicated system which involves polar and non-polar species in phase splitting [26]. The model is based on local composition theory that considers the effect of mixture composition towards mixture interaction. It consists of two contributions - combinatorial term to indicate the geometric significance for molecules of different sizes and shapes, and residual term to include the energetic parameters [27].

In the UNIQUAC model, the activity coefficient $\left(\gamma_{\mathrm{i}}\right)$ was predicted by the following equations.

$$
\begin{gathered}
\ln \gamma_{i}=\ln \gamma_{i}^{C}+\ln \gamma_{i}^{R} \\
\ln \gamma_{i}^{C}=\ln \frac{\psi_{i}}{x_{i}}+\left(\frac{\bar{Z}}{2}\right) q_{i} \ln \frac{\theta_{i}}{\psi_{i}}+l_{i}-\left(\frac{\psi_{i}}{x_{i}}\right) \sum_{j=1}^{C} x_{j} l_{j} \\
\ln \gamma_{i}^{R}=q_{i}\left[1-\ln \left(\sum_{j=1}^{C} \theta_{j} \tau_{i j}\right)-\sum_{j=1}^{C}\left(\frac{\theta_{j} \tau_{i j}}{\sum_{k=1}^{C} \theta_{k} \tau_{k j}}\right)\right]
\end{gathered}
$$

where

$$
\begin{gathered}
l_{i}=\left(\frac{\bar{Z}}{2}\right)\left(r_{i}-q_{i}\right)-\left(r_{i}-1\right) \\
\psi_{i}=\frac{x_{i} r_{i}}{\sum_{i=1}^{C} x_{i} r_{i}} \\
\theta_{i}=\frac{x_{i} q_{i}}{\sum_{i=1}^{C} x_{i} q_{i}} \\
r_{i}=\sum_{g} v_{g(i)} S_{g} \\
q_{i}=\sum_{g} v_{g(i)} Q_{g} \\
\bar{Z}=10 \\
\tau_{i j}=\exp \left(\frac{\mu_{i j}-\mu_{j j}}{R T}\right)
\end{gathered}
$$

$r_{i}$ and $q_{i}$ are the volume and surface area paramteres of compound $i$. They were computed from bond angle and bond distance and were estimated by group-contribution method using tabulated $S_{g}$ and $Q_{g}$ values from [28] and [29]. $v_{g(i)}$ is the number of functional group $\mathrm{g}$ for compound $i, x_{i}$ is the mole fraction of compound $i$. For each binary pair, there were two binary interaction coefficients $\left(\tau_{i j}\right)$ that were adjusted by experimental data. They were determined using Microsoft solver through minimization of the objective function (OF). 


$$
\begin{gathered}
K_{i}=\frac{x_{i}^{[1]}}{x_{i}^{[2]}}=\frac{\gamma_{i}^{[2]}}{\gamma_{i}^{[1]}} \\
\mathrm{OF}=\sum_{\text {all points }}\left(K_{x}-K_{\gamma}\right)^{2}
\end{gathered}
$$

where $K_{x}$ is the distribution coefficient as obtained by experimental data while $K_{\gamma}$ is calculated from activity coefficient, which is obtained from an initial guess of three pairs of binary interaction coefficients $\left(\tau_{i j}\right)$. Superscripts [1] and [2] are solvent-rich and oil-rich phases, respectively.

For the prediction of the behavior of liquid-liquid equilibrium, the fitted and calculated UNIQUAC parameters were utilized to construct ternary diagrams for the pseudoternary systems of palm oil + ethyl lactate + $\beta$-carotene or $\gamma$-tocotrienol at $303.15 \mathrm{~K}$.

\section{RESULTS AND DISCUSSION}

Fig. 1 shows the cloud point for the binary system of palm oil + ethyl lactate. The system exhibits UCST at approximately 0.65 mass fraction of ethyl lactate, with the critical point at $320 \mathrm{~K}$. [21] reported a binary system of olive oil + ethyl lactate as the UCST was found at $311.2 \mathrm{~K}$. This suggests that ethyl lactate exerts better miscibility with olive oil than with palm oil. The cloud point data is useful to determine the biphasic condition in liquid-liquid extractors. Within the bell curve, the binary system would settle into two phases while homogeneous single phase exists outside the curve.

Table I presents the overall composition and the corresponding tie lines for the pseudoternary systems composed of palm oil + ethyl lactate $+\beta$-carotene and $\gamma$-tocotrienol.

In the thermodynamic modeling, palm oil was represented by a single component, which is composed of glycerol backbone with an equal number of palmitic and oleic acid side chains. This simplification was based on the fact that the two major fatty acids in palm oil are palmitic $(43.7 \%)$ and oleic acids $(39.9 \%)$. As $\beta$-carotene and $\gamma$-tocotrienol are the major carotene and tocol in palm oil, they were used to model carotenes and tocols in palm oil, respectively. This approach assumes that the different triglycerides, carotenes and tocols behave similarly in the liquid-liquid system under analysis.

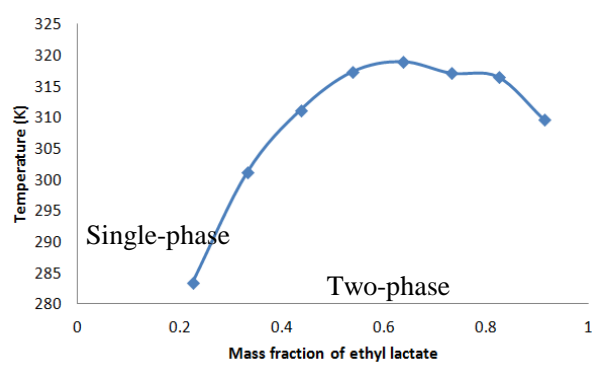

Fig. 1. Cloud point with respect to mass fraction of ethyl lactate for the binary mixture of palm oil + ethyl lactate at atmospheric pressure.

TABLE I: LIQUID-LIQUID EQUILIBRIUM DATA FOR THE TERNARY SYSTEMS OF PALM OIL (1) + ETHYL LACTATE (2) + BETA-CAROTENE (3) AND

\begin{tabular}{|c|c|c|c|c|c|c|c|c|}
\hline \multicolumn{3}{|c|}{ Overall Composition } & \multicolumn{3}{|c|}{ Solvent-rich phase } & \multicolumn{3}{|c|}{ Oil-rich phase } \\
\hline$X_{1}$ & $\mathrm{X}_{2}$ & $\mathrm{X}_{3}$ & $\mathrm{X}_{1}$ & $\mathrm{X}_{2}$ & $\mathrm{X}_{3}$ & $\mathrm{X}_{1}$ & $\mathrm{X}_{2}$ & $\mathrm{X}_{3}$ \\
\hline 0.1065 & 0.8934 & $1.5676 \times 10^{-4}$ & 0.0142 & 0.9858 & $2.1067 \times 10^{-5}$ & 0.1878 & 0.8120 & $2.7450 \times 10^{-4}$ \\
\hline 0.1065 & 0.8934 & $5.2398 \times 10^{-5}$ & 0.0139 & 0.9861 & $9.7709 \times 10^{-6}$ & 0.1878 & 0.8121 & $8.9773 \times 10^{-5}$ \\
\hline 0.0572 & 0.9427 & $1.3283 \times 10^{-4}$ & 0.0125 & 0.9874 & $2.2093 \times 10^{-5}$ & 0.1941 & 0.8055 & $4.7439 \times 10^{-4}$ \\
\hline 0.0571 & 0.9429 & $9.4545 \times 10^{-5}$ & 0.0127 & 0.9873 & $2.0449 \times 10^{-5}$ & 0.1930 & 0.8067 & $3.2160 \times 10^{-4}$ \\
\hline 0.0796 & 0.9203 & $1.0695 \times 10^{-4}$ & 0.0133 & 0.9866 & $1.6490 \times 10^{-5}$ & 0.1900 & 0.8097 & $2.5762 \times 10^{-4}$ \\
\hline 0.1103 & 0.8895 & $1.9644 \times 10^{-4}$ & 0.0147 & 0.9853 & $2.1803 \times 10^{-5}$ & 0.1876 & 0.8121 & $3.3885 \times 10^{-4}$ \\
\hline 0.0794 & 0.9205 & $1.4754 \times 10^{-4}$ & 0.0132 & 0.9868 & $1.8161 \times 10^{-5}$ & 0.1895 & 0.8102 & $3.6419 \times 10^{-4}$ \\
\hline $\mathrm{X}_{1}$ & $\mathrm{X}_{2}$ & $\mathrm{X}_{4}$ & $\mathrm{X}_{1}$ & $\mathrm{X}_{2}$ & $\mathrm{X}_{4}$ & $\mathrm{X}_{1}$ & $\mathrm{X}_{2}$ & $\mathrm{X}_{4}$ \\
\hline 0.0434 & 0.9563 & $3.1460 \times 10^{-4}$ & 0.0109 & 0.9889 & $2.2670 \times 10^{-4}$ & 0.2210 & 0.7782 & $7.9415 \times 10^{-4}$ \\
\hline 0.0611 & 0.9387 & $1.4143 \times 10^{-4}$ & 0.0126 & 0.9874 & $8.9130 \times 10^{-5}$ & 0.2205 & 0.7792 & $3.1385 \times 10^{-4}$ \\
\hline 0.0423 & 0.9574 & $2.9283 \times 10^{-4}$ & 0.0114 & 0.9884 & $2.1247 \times 10^{-4}$ & 0.2266 & 0.7726 & $7.7083 \times 10^{-4}$ \\
\hline 0.0569 & 0.9428 & $3.2376 \times 10^{-4}$ & 0.0107 & 0.9891 & $1.9704 \times 10^{-4}$ & 0.2209 & 0.7783 & $7.7399 \times 10^{-4}$ \\
\hline 0.0995 & 0.9001 & $3.4604 \times 10^{-4}$ & 0.0115 & 0.9883 & $1.6463 \times 10^{-4}$ & 0.2255 & 0.7739 & $6.0434 \times 10^{-4}$ \\
\hline
\end{tabular}
GAMMA-TOCOTRIENOL (4) AT 303.15 K

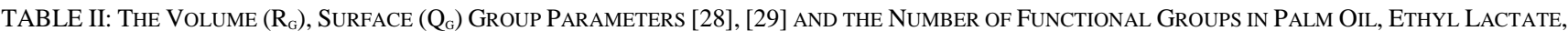

\begin{tabular}{|c|c|c|c|c|c|c|}
\hline Functional group (g) & $\mathrm{R}_{\mathrm{g}}$ & $\mathrm{Qg}_{\mathrm{g}}$ & Palm oil & Ethyl lactate & $\beta$-carotene & $\gamma$-tocotrienol \\
\hline $\mathrm{CH}_{3}$ & 0.9011 & 0.848 & 3 & 2 & 8 & 4 \\
\hline $\mathrm{CH}_{2}$ & 0.6744 & 0.540 & 42 & - & 5 & 8 \\
\hline $\mathrm{CH}$ & 0.4469 & 0.228 & - & 1 & 1 & - \\
\hline $\mathrm{C}$ & 0.2195 & 0 & - & - & 2 & - \\
\hline $\mathrm{CH}=\mathrm{CH}$ & 1.1167 & 0.867 & 1.5 & - & 5 & - \\
\hline $\mathrm{CH}=\mathrm{C}$ & 0.8886 & 0.676 & - & - & 4 & 3 \\
\hline $\mathrm{ACH}$ & 0.5313 & 0.400 & - & - & 1 & 1 \\
\hline $\mathrm{AC}$ & 0.3652 & 0.120 & - & - & 1 & 2 \\
\hline $\mathrm{ACCH}_{3}$ & 1.2663 & 0.968 & - & - & 2 & 2 \\
\hline $\mathrm{OH}$ & 1.0000 & 1.200 & - & 1 & - & - \\
\hline $\mathrm{ACOH}$ & 0.8952 & 0.6800 & - & - & - & 1 \\
\hline $\mathrm{CH}_{3} \mathrm{CO}$ & 1.6724 & 1.4880 & - & - & - & 1 \\
\hline $\mathrm{CH}_{2} \mathrm{COO}$ & 1.6764 & 1.420 & 3 & 1 & - & - \\
\hline
\end{tabular}
BETA-CAROTENE AND GAMMA-TOOCTRIENOL 
TABLE III: MOLECULAR WEIGHT, VOLUME AND SURFACE PARAMETERS FOR PALM OIL, ETHYL LACTATE, B-CAROTENE AND Г-TOCOTRIENOL

\begin{tabular}{lccc}
\hline \hline Component i & $\begin{array}{c}\text { Molecular } \\
\text { weight } \\
(\mathrm{g} / \mathrm{mol})\end{array}$ & $r_{i}$ & $q_{i}$ \\
\hline Palm oil & 846 & 37.7324 & 30.785 \\
Ethyl lactate & 118 & 4.9255 & 4.544 \\
$\beta$-carotene & 536 & 24.0337 & 19.207 \\
$\gamma$-tocotrienol & 410 & 18.0273 & 14.484 \\
\hline \hline
\end{tabular}

TABLE IV: BINARY INTERACTION PARAMETERS FOR SYSTEMS COMPRISINC PALM OIL, ETHYL LACTATE, BETA-CAROTENE AND GAMMA-TOCOTRIENOL. VALUES AS OBTAINED BY GAMMA-TOCOTRIENOL MODEL ARE REPRESENTED IN BRACKETS.

\begin{tabular}{cccc}
\hline \hline Component $\mathrm{i}$ & Component $\mathrm{j}$ & $\tau_{i j}$ & $\tau_{j i}$ \\
\hline Palm oil & Ethyl lactate & 0.7705 & 1.0039 \\
& & $(0.7242)$ & $(1.0405)$ \\
Palm oil & $\beta$-carotene & 0.03704 & 0.0029 \\
Palm oil & $\gamma$-tocotrienol & $(0.0435)$ & $(2.8781)$ \\
Ethyl lactate & $\beta$-carotene & 0.01224 & 1.0193 \\
Ethyl lactate & $\gamma$-tocotrienol & $(0.0099)$ & $(4.6452)$ \\
\hline \hline
\end{tabular}
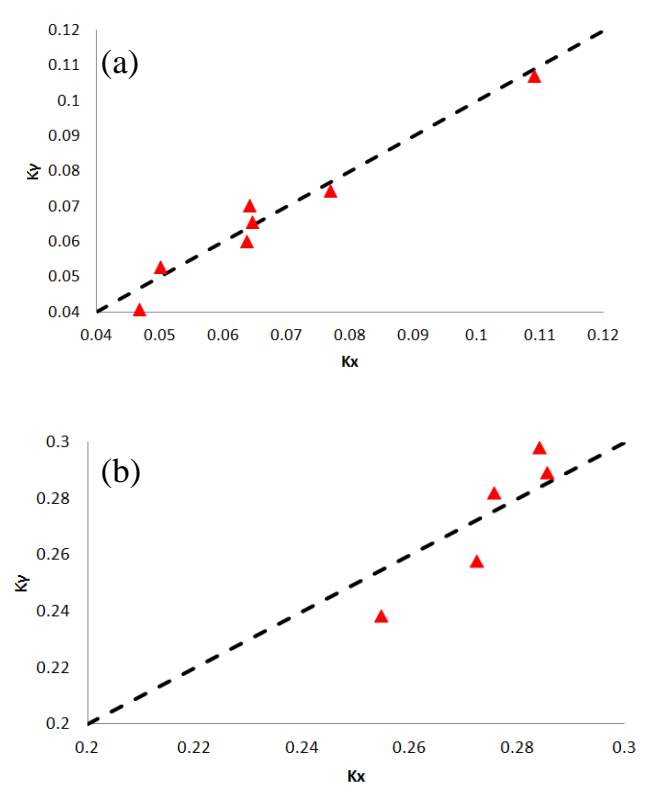

Fig. 2. The comparison of $\mathrm{K}_{\mathrm{x}}$ and $\mathrm{K}_{\gamma}$ for $\beta$-carotene (a) and $\gamma$-tocotrienol (b).

The volume $\left(\mathrm{R}_{\mathrm{g}}\right)$, surface $\left(\mathrm{Q}_{\mathrm{g}}\right)$ group parameters and the number of functional groups in palm oil, ethyl lactate, $\beta$-carotene and $\gamma$-tocotrienol are tabulated in Table II. The volume and surface area parameters as calculated through functional-group contribution method for each of the component (palm oil, ethyl lactate, $\beta$-carotene and $\gamma$-tocotrienol) are tabulated in Table III.

The most reliable procedure for the determination of UNIQUAC model parameters involves a fit to available experimental data over a wide range of liquid compositions. For the binary system of palm oil + ethyl lactate, the interaction parameters $\left(\tau_{\mathrm{ij}}\right)$ were determined as the first guess for the ternary systems. It is not uncommon for the OF in such nonlinear parameter estimation problems to be non-convex and thus have several local minima. Because the methods typically used to solve such problems, like the one used in the present study, are local methods that are strongly dependent on the initial estimates applied, they provide no guarantee that the global optimum has been found. Thus, the sets of the binary interaction parameters obtained likely represent just one of the possible sets of parameters [20]. The binary interaction parameters as adjusted by the experimental data through model fitting are tabulated in Table IV. The OF for $\beta$-carotene and $\gamma$-tocotrienol models were obtained at 0.000149 and 0.0104 , respectively, which were very near to zero. The comparison of $K_{x}$ and $K_{\gamma}$ is presented in Fig. 2. The deviations were calculated at $5.7 \%$ and $4.1 \%$ for $\beta$-carotene and $\gamma$-tocotrienol, respectively.

Fig. 3 shows the comparison between the experimental liquid-liquid equilibrium data and their values as simulated by UNIQUAC thermodynamic model. As can be observed from the figure, good representation of liquid-liquid equilibrium is achieved in $\beta$-carotene model. As for the model of $\gamma$-tocotrienol, deviations are greater in the solvent-rich phase at higher concentration of $\gamma$-tocotrienol when UNIQUAC model parameters underestimated the amount of $\gamma$-tocotrienol extracted. An alternative thermodynamic model, non-random two-liquid (NRTL) may be considered for better accuracy even at high $\gamma$-tocotrienol concentration. In [24], the comparison of UNIQUAC and NRTL models were presented, it was found that UNIQUAC underestimated the extraction of FFA at high concentration even though no difference was found for tocopherols by assuming infinite dilution in cottonseed oil and ethanol. The average percentage of deviations was calculated at $4.10 \%$ and $9.98 \%$, respectively, by (13).

$$
100 \sqrt{\frac{\sum_{n=1}^{N} \sum_{i=1}^{C}\left[\left(x_{i, n}^{I, e x p}-x_{i, n}^{I, \text { calc }}\right)^{2}+\left(x_{i, n}^{I, \text { exp }}-x_{i, n}^{I, \text {, calc }}\right)^{2}\right.}{2 N C}}
$$

where $N$ represents the number of tie lines while $\mathrm{C}$ represents the number of compounds.

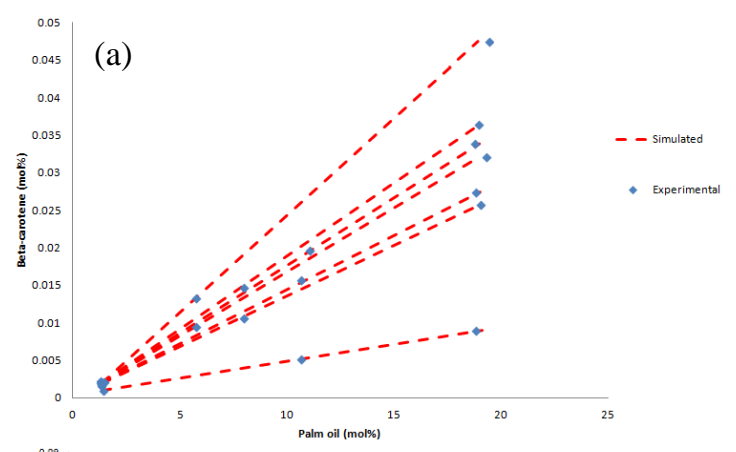

(b)

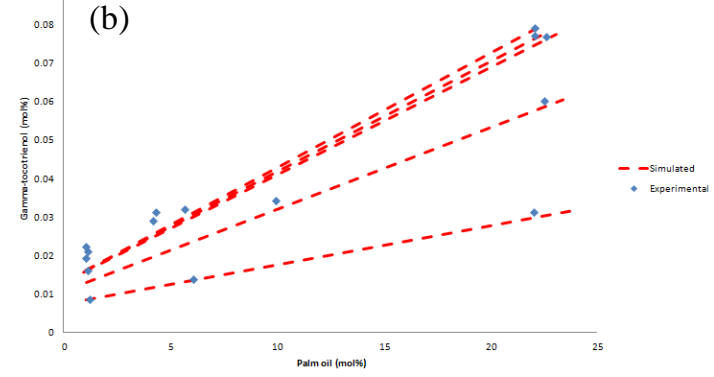

Fig. 3. The experimental and simulated liquid-liquid equilibrium data for the systems of palm oil + ethyl lactate $+\beta$-carotene (a) and $\gamma$-tocotrienol (b).

Fig. 4 shows the separation factors as plotted against $\beta$-carotene and $\gamma$-tocotrienol initial concentration in palm oil. Separation factor is defined by (14) and it is a measure of the system selectivity towards the partition of $\beta$-carotene and $\gamma$-tocotrienol from oil. It was found that the separation factors are reducing for $\beta$-carotene but increasing for $\gamma$-tocotrienol. 
This suggests that the separation factor improved with lower concentration of carotenes and higher concentration of tocols in palm oil using ethyl lactate as the solvent. This is similar to the results reported by [21] when the separation factors increased with the concentration of $\alpha$-tocopherol in olive oil using ethyl lactate. The average separation factor as obtained in this work (5.4) is slightly higher than [21] at 4.9. This may be due to the use of higher temperature at $303.15 \mathrm{~K}$ as compared to [21] at 298.15 K. As compared to $\gamma$-tocotrienol, the average separation factor of $\beta$-carotene is lower at 0.9 . Similar results were obtained by [23] as more tocopherols were extracted than carotenoids from palm oil using ethanol as the solvent.

$$
\text { Separation factor }=\frac{K_{\beta} \text {-carotene or } \gamma \text {-tooctrienol }}{K_{\text {oil }}}
$$

With the use of ethyl lactate as the solvent, the tendency towards the extraction of tocotrienol is greater than carotene. Even though both carotene and tocotrienol are non-polar in nature, tocotrienol is relatively more polar due to the presence of the hydroxyl and triene groups. Therefore, it has higher solubility into ethyl lactate, which is polar. By dissolving excessive $\beta$-carotene in ethyl lactate at $303.15 \mathrm{~K}$, it was found that the saturation concentration was $310.15 \mathrm{mg} / \mathrm{L}$, which is quite low. Thus, it is the maximum extractive capability of ethyl lactate towards $\beta$-carotene. Any increase of the $\beta$-carotene concentration will not enhance but reduce the separation factor.
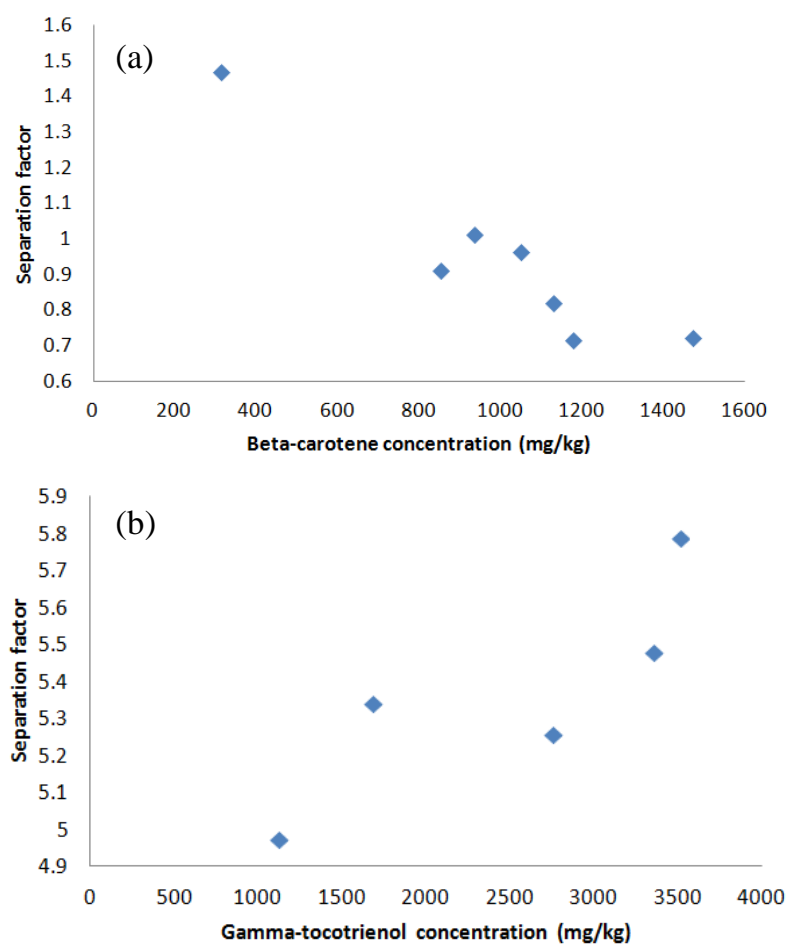

Fig. 4. The separation factor with respect to the initial concentration of $\beta$-carotene (a) and $\gamma$-tocotrienol (b) in palm oil.

Even though the increase of the mass \% of ethyl lactate did not improve the distribution coefficients for both carotene and tocotrienol, the \% mass recovery by (15) could be enhanced, provided the mixture (with higher mass \% of ethyl lactate) is still within the biphasic condition (within the curve of Fig. 1). As refer to Fig. 5, the increase of the mass $\%$ of ethyl lactate promoted the $\%$ mass recovery for both carotene and tocotrienol. For comparison, mass recovery of $16 \%$ and $48 \%$ of carotene and tocotrienol were achieved at 70 mass $\%$ of ethyl lactate. Again, more tocotrienol was extracted due to its higher polarity than carotene.

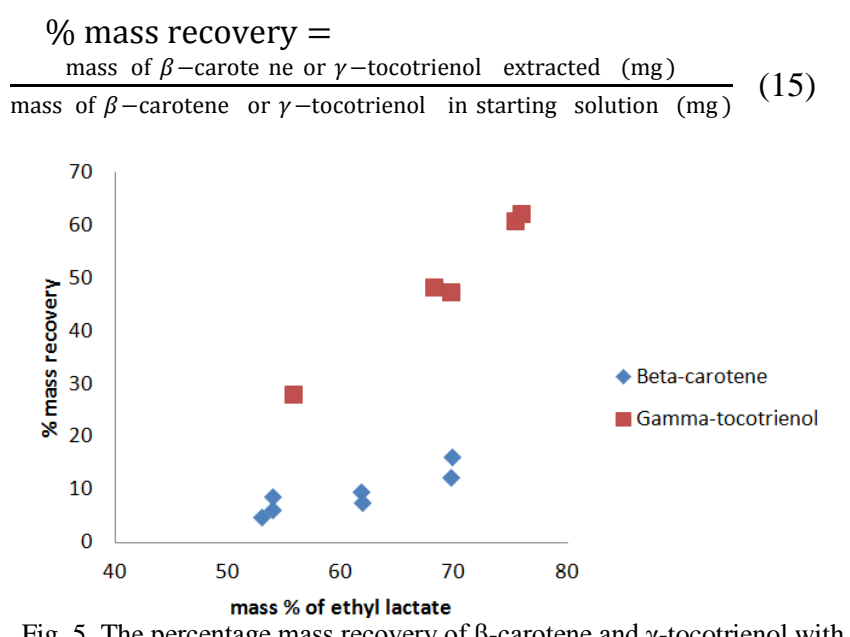

Fig. 5. The percentage mass recovery of $\beta$-carotene and $\gamma$-tocotrienol with increasing mass percentage of ethyl lactate.

\section{CONCLUSION}

UNIQUAC thermodynamic model was demonstrated for the first time for the two ternary systems of palm oil + ethyl lactate $+\beta$-carotene and $\gamma$-tocotrienol. The presented data enables the design of liquid-liquid extractors for palm carotenes and tocols recovery using ethyl lactate. The studies in this work showed the feasibility of ethyl lactate as a safe and green agrochemical solvent to extract carotenes and tocols from palm oil. The average separation factor of 0.9 and 5.4 were reported for $\beta$-carotene and $\gamma$-tocotrienol, respectively. Also, recovery of $16 \%$ of $\beta$-carotene and $48 \%$ of $\gamma$-tocotrienol were achieved in a single stage at 70 mass $\%$ of ethyl lactate. As the implementation of multistage is not uncommon for liquid-liquid extraction, the yield will be further improved. NRTL could be considered to model $\gamma$-tocotrienol system in an effort to improve the accuracy at higher concentration.

\section{REFERENCES}

[1] M. Choo, A. S. H. Ong, S. H. Goh, and H. T. Khor, "Transesterification of fats and oils," U. S. Patent 2188057, 1990.

[2] B. Nagendran, U. R. Unithan, Y. M. Choo, and K. Sundram, "Characteristics of red palm oil, a carotene and vitamin E-rich refined oil for food uses," Food and Nutrition Bulletin, vol. 21, pp. 189-194, 2000 .

[3] K. Sundram, R. Sambanthamurthi, and Y. A. Tan, "Palm fruit chemistry and nutrition," Asia Pacific Journal of Clinical Nutrition, vol. 12, no. 3, pp. 355-362, 2003.

[4] Y. J. Suzuki, M. Tsuchiya, S. R. Wassall, Y. M. Choo, G. Govil, V. E. Kagan, and L. Packer, "Structural and dynamic membrane properties of $\alpha$-tocopherol and $\alpha$-tocotrienol: Implication to the molecular mechanism of their antioxidant potency," Biochemistry, vol. 32, no. 40, pp. 10692-10699, 1993.

[5] Y. Gopalan, I. L. Shuaib, E. Magosso et al., "Clinical investigation of the protective effects of palm vitamin E tocotrienols on brain white matter," Stroke, vol. 45, no. 5, pp. 1422-1428, 2014.

[6] E. Magosso, M. A. Ansari, Y. Gopalan et al., "Tocotrienols for normalization of hepatic echogenic response in non-alcoholic fatty liver: A randomized placebo-controlled clinical trial," Nutritional Journal, vol. 12, no. 1, p. 166, 2013.

[7] L. Packer, S. U. Weber, and G. Rimbach, "Molecular aspects of $\alpha$-tocotrienol antioxidant action and cell signaling," Journal of Nutrition, vol. 131, pp. 369S-373S, 2001. 
[8] A. Theriault, C. Jun-Tzu, Q. Wang, A. Gapor, and K. Adeli, "Tocotrienol: A review of its therapeutic potential," Clinical Biochemistry, vol. 32, pp. 309-319, 1999.

[9] A. S. H. Ong, "Natural sources of tocotrienols," in Vitamin E in Health and Disease, L. Packer and J. Fuchs, Eds. New York: Mercel Dekker, 1993, pp. 3-8.

[10] USDA. (2016). Oilseeds: World markets and trade. United States Department of Agriculture. [Online]. Available: http://apps.fas.usda.gov/psdonline/circulars/oilseeds.pdf

[11] S. Aparicio, S. Hallajian, R. Alcalde, B. Garcia, and J. M. Leal, "Liquid structure of ethyl lactate, pure and water mixed, as seen by electric spectroscopy, solvatochromic and thermophysical studies," Chemical Physics Letters, vol. 454, pp. 49-55, 2008.

[12] J. Drapeau, M. Verdier, D. Touraud, U. Krockel, M. Geier, A. Rose, and W. Kunz, "Effective insect repellent formulation in both surfactantless and classical microelmulsions with a long-lasting protection for human beings," Chemistry and Biodiversity, vol. 6, pp. 934-947, 2009

[13] I. F. Strati and V. Oreopoulou, "Effect of extraction parameters on the carotenoid recovery from tomato waste," International Journal of Food Science and Technology, vol. 46, pp. 23-29, 2011.

[14] D. V. Bermejo, E. Ibáñez, G. Reglero, C. Turner, T. Fornari, and I. R. Meizoso, "High catechins/low caffeine powder from green tea leaves by pressurized liquid extraction and supercritical antisolvent precipitation," Separation and Purification Technology, vol. 148, pp. 49-56, 2015.

[15] M. T. Golmakani, J. A. Mendiola, K. Rezaei, and E. Ibanez, "Greener solvents for old challenge," The $10^{\text {th }}$ International Symposium on Supercritical Fluids, 2012.

[16] B. K. Ishida and M. H. Chapman, "Carotenoid extraction from plants using novel, environmentally friendly solvent," Journal of Agricultural and Food Chemistry, vol. 57, pp. 1051-1059, 2009.

[17] M. Lores, M. Pájaro, M. A. Casas, J. Domínguez, and C. G. Jares, "Use of ethyl lactate to extract bioactive compounds from Cytisus scoparius Comparison of pressurized liquid extraction and medium scale ambient temperature systems," Talanta, vol. 140, pp. 134-142, 2015.

[18] D. Villanueve, P. Luna, M. Manic, V. Najdanovic-Visak, and T. Fornari, "Extraction of caffeine from green coffee beans using ethyl lactate," $9^{\text {th }}$ Green Chemistry Conference, 2011.

[19] W. Wu, M. B. Lu, and L. J. Yu, "A new environmentally friendly method for astaxanthin extraction from Xanthophyllomyces dendroohous," European Food Research and Technology, vol. 232, pp. 463-467, 2011.

[20] E. J. Hernandez, P. Luna, R. P. Stateva, V. N. Visak, G. Reglero, and T. Fornari, "Liquid-liquid phase transition of mixtures comprising squalene, olive oil, and ethyl lactate: Application to recover squalene from oil deodorizer distillates," Journal of Chemical and Engineering Data, vol. 56, pp. 2148-2152, 2011.

[21] G. Vicente, A. Paiva, T. Fornari, and V. N. Visak, "Liquid-liquid equilibria for separation of tocopherol from olive oil using ethyl lactate," Chemical Engineering Journal, vol. 172, pp. 879-884, 2011.

[22] M. Ansolin, R. C. Basso, A. J. A. Meirelles, and E. A. C. Batista, "Experimental data for liquid-liquid equilibrium of fatty systems with emphasis on the distribution of tocopherols and tocotrienols," Fluid Phase Equilibria, vol. 338, pp. 78-86, 2013.

[23] C. B. Gonçalves, P. A. P. Filho, and A. J. A. Meirelles, "Partition of nutraceutical compounds in deacidification of palm oil by solvent extraction," Journal of Food Engineering, vol. 81, pp. 21-26, 2007.

[24] C. E. C. Rodrigues, E. C. D. Reipert, A. F. Souza, P. A. P. Filho, and A. J. A. Meirelles, "Equilibrium data for systems composed by cottonseed oil + commercial linoleic acid + ethanol + water + tocopherols at 298.2K," Fluid Phase Equilibria, vol. 238, pp. 193-203, 2005.

[25] D. S. Abrams and J. M. Prausnitz, "Statistical thermodynamics of liquid mixtures: A new expression for the excess gibbs energy of partly or completely miscible systems," AIChE Journal, vol. 21, No. 1, pp. 116-128, 1975.

[26] J. D. Seader and E. J. Henley, Separation Process Principles: Liquid Extraction of Ternary Systems, $2^{\text {nd }}$ ed. John Wiley \& Sons, Inc., 2006, pp. 295-298.

[27] J. R. Elliot and C. T. Lira, Introductory Chemical Engineering Thermodynamics, Prentice Hall, 1999, pp. 388-403.

[28] A. Fredenslund, R. L. Jones, and J. M. Prausnitz, "Group-contribution estimation of activity coefficients in nonideal liquid mixtures," AIChE Journal, vol. 21, no. 6, pp. 1086-1099, 1975.

[29] T. Mgnussen, P. Rasmussen, and A. Fredenslund, "UNIFAC parameter table for prediction of liquid-liquid equilibria," Industrial \& Engineering Chemistry Process Design and Development, vol. 20, pp. 331-339, 1981.

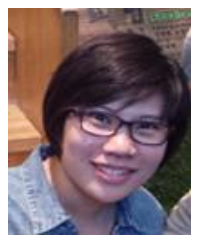

Y. L. Kua completed her undergraduate master degree in chemical engineering from the University of Nottingham Malaysia Campus in 2011. Later, she worked as an engineer in the industry of electroplating/inorganic coating on rare-earth magnets with the Shin-Etsu Chemical company before continuing her postgraduate study in the same university in 2014. Currently, she is a research assistant and $\mathrm{PhD}$ candidate for the project of green extraction technology of palm carotenes and tocols using ethyl lactate.

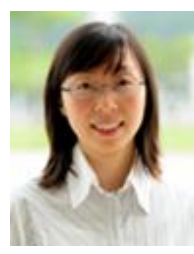

S. Gan is currently a professor of chemical engineering at the Department of Chemical and Environmental Engineering, University of Nottingham Malaysia Campus. Prof. Gan works in a wide range of interdisciplinary experimental and computational activities within the central theme of energy and fuels. She has over 130 publications to date in internationally refereed journals, technical papers, congress/conference proceedings and book chapters. She has led projects which are funded by government organizations, industry and university. She also serves on the editorial board of two international journals.

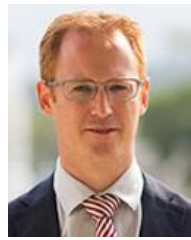

A. Morris graduated from the Welsh School of Pharmacy (Cardiff, UK) in 1998. After registering as a pharmacist with the Royal Pharmaceutical Society of Great Britain (RPSGB), he subsequently returned to Cardiff to carry out his doctoral studies in the area of transdermal drug delivery. After joining the University of Nottingham in 2005, Prof. Morris was relocated to Malaysia where he established the first ever RPSGB-accredited Pharmacy programme outside of the UK. In 2010, he became the Director of Studies of the MPharm degree at University of Nottingham Malaysia Campus. He is currently both Dean of the Faculty of Science as well as Head of the School of Pharmacy. He has published widely in a variety of international journals.

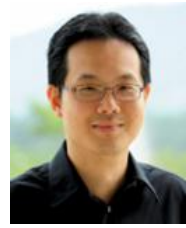

H. K. Ng is a Professor of Mechanical Engineering and the Head of the Department of Mechanical, Materials and Manufacturing Engineering, University of Nottingham Malaysia Campus. Prof. Ng also served as the Head for the research division of Energy, Fuel and Power Technology and as the founding deputy director of the Asia Aerospace City Research and Technology Centre. He has well over 140 publications to date in internationally refereed journals technical papers, congress/conference proceedings and book chapters. He has led a number of projects which are funded by government organizations, industry and university. 